\title{
The Effects of Verapamil, Hydralazine, and Doxazosin on Renin, Aldosterone, and the Ratio Thereof
}

\author{
Gregory P. Veldhuizen ${ }^{1} \cdot$ Rawan M. Alnazer $^{1} \cdot$ Peter W. de Leeuw $^{1}$ (1) $\cdot$ Abraham A. Kroon $^{1}$
}

Accepted: 6 September 2021 / Published online: 13 September 2021

(c) The Author(s) 2021

\begin{abstract}
Purpose Hydralazine, doxazosin, and verapamil are currently recommended by the Endocrine Society as acceptable bridging treatment in those in whom full cessation of antihypertensive medication is infeasible during screening for primary aldosteronism (PA). This is under the assumption that they cause minimal to no effect on the aldosterone-to-renin ratio, the most widely used screening test for PA. However, limited evidence is available regarding the effects of these particular drugs on said ratio.

Methods In the present study, we retrospectively assessed the changes in aldosterone, renin, and aldosterone-to-renin values in essential hypertensive participants before and after treatment with either hydralazine $(n=26)$ or doxazosin $(n=20)$ or verapamil $(n=15)$. All samples were taken under highly standardized conditions.

Results Hydralazine resulted in a borderline significant rise in active plasma renin concentration ( $19 \mathrm{vs} 25 \mathrm{mIU} / \mathrm{L}, p=0.067$ ) and a significant fall in the aldosterone-to-renin ratio (38 vs $24, p=0.017$ ). Doxazosin caused declines in both plasma aldosterone concentration (470 vs $330 \mathrm{pmol} / \mathrm{L}, p=0.028)$ and the aldosterone-to-renin ratio (30 vs 20, $p=0.020)$. With respect to verapamil, we found no statistically significant effect on any of these outcome variables.

Conclusion We conclude that the assumption that these drugs can be used with little consequence to the aldosterone-to-renin cannot be substantiated. While it is possible that they are indeed the best option when full antihypertensive drug cessation is infeasible, the potential effects of these drugs must still be taken into account when interpreting the aldosterone-to-renin ratio.
\end{abstract}

Keywords Renin-aldosterone ratio $\cdot$ Verapamil $\cdot$ Hydralazine $\cdot$ Doxazosin

\section{Introduction}

The aldosterone-to-renin ratio (ARR) is the most widely used screening test for primary aldosteronism (PA) and is recommended by current guidelines [1]. However, due to the potential effects that antihypertensive drugs may have on the renin-angiotensin-aldosterone system (RAAS), these guidelines advocate to cease antihypertensive medication prior to ARR screening whenever possible. In many patients, however, such a strategy is infeasible. In the event that cessation of antihypertensive agents is not possible, the current Endocrine Society guidelines recommend switching

Peter W. de Leeuw

p.deleeuw@maastrichtuniversity.nl

1 Dept of Internal Medicine, Maastricht University Medical Center and Cardiovascular Research Institute Maastricht (CARIM), PO Box 5800, Maastricht 6202, AZ, The Netherlands to verapamil, hydralazine, or an $\alpha$-adrenergic blocker such as doxazosin on the assumption that these drugs exert noto-minimal effects on the RAAS [1]. While the theoretical background for their largely neutral effect on the ARR is strong, a recent review article found that no robust studies investigating the effects of verapamil and hydralazine on the ARR have been performed [2]. Specifically, studies have usually assessed average changes in renin and aldosterone but not the individual changes in ARR. In addition, only one study has addressed the effects of doxazosin and very notably showed that both aldosterone and ARR values significantly fell during treatment with that drug [3]. The objective of the present study, therefore, is to investigate the effects that verapamil, hydralazine, and doxazosin may have on the ARR in individual patients. To this end, we reassessed the data from three patient groups which we studied earlier for changes in renin and aldosterone during those treatments. We hypothesized that none of the medications under scrutiny would significantly affect the ARR. 


\section{Patients and Methods}

\section{Study Population}

A total of 61 Caucasian Dutch patients who had been referred to our hypertension clinic for evaluation of their hypertension participated in the three studies. Of these, 26, 20 , and 15 had been treated with hydralazine, doxazosin, and verapamil, respectively. Except for being hypertensive, none of the patients had any concomitant disease, such as diabetes or reduced renal function. Nevertheless, slightly over half of them were overweight.

All active treatment phases were preceded by a placebo run-in period.

All participants gave informed consent to partake in this study which was approved by the Institutional Review Board.

Secondary causes of hypertension were ruled out after appropriate diagnostic procedures. These included measurements of active plasma renin concentration (APRC), plasma aldosterone concentration (PAC), calculation of the ARR, and additional tests such as saline loading if indicated. In case secondary hypertension was diagnosed, patients were excluded from this study.

\section{Procedures}

As part of our routine diagnostic work-up for secondary hypertension, we discontinued any antihypertensive medication for 3 weeks when this could be safely withheld. All measurements took place within this time window. After the initial assessment, during which participants were given a placebo tablet, they were treated with the respective drugs for at least 2 weeks prior to repeat testing. Doses were uptitrated until blood pressure was 140/90 $\mathrm{mmHg}$ or below.

All investigations took place in a metabolic ward to which patients had been admitted prior to the investigations. On the day of testing, after an overnight fast and complete bed rest for $10 \mathrm{~h}$, participants stayed in the laboratory from 08:00 a.m. until noon. After we had inserted an indwelling needle into the right antecubital vein, patients were allowed to rest for another $45 \mathrm{~min}$. Thereafter, we took the first blood sample for determination of untreated plasma active renin and untreated plasma aldosterone concentrations (U-APRC and U-PAC respectively). All blood samples were taken in the supine position. Blood was collected in chilled tubes and spun immediately under cooled conditions and the plasma was stored at $-80^{\circ} \mathrm{C}$ until assay. This process was repeated after participants had been placed on their respective drug regimens to determine their treated APRC and PAC values (T-APRC and T-PAC respectively).
Throughout the entire period, blood pressure was measured at 5-min intervals with an automatic, oscillometric device (Dinamap, Tampa, FL), while patients remained in the supine position until the end of the study.

APRC was measured by a direct immunoradiometric assay that detects active renin. Its characteristics are as follows: sensitivity $2.5 \mathrm{mIU} / \mathrm{L}$, intra-assay variability $2.6 \%$, and inter-assay variability $4.3 \%$. PAC was measured by solidphase radioimmunoassay (antibody-coated tubes) with a sensitivity of $55 \mathrm{pmol} / \mathrm{L}$, an intra-assay variability of $4.3 \%$, and an inter-assay variability of $6.7 \%$. Untreated and treated ARR (U-ARR and T-ARR, respectively) were calculated from the respective PAC and APRC results.

\section{Statistical Methods}

Using IBM SPSS Statistics Version 26 for Windows for all analyses, we first confirmed the normality of distribution of all data. The ones from the verapamil and doxazosin populations (VP and DP respectively) were both normally distributed, but those from the hydralazine population (HP) required log transformations before analysis. We performed paired t-tests on all groups comparing U-APRC and T-APRC, U-PAC and T-PAC, and U-ARR and T-ARR. Multiple regression analyses were performed to assess possible confounding by age, sex, and BMI on changes in APRC, PAC, and ARR during treatment.

For all analyses, a $p$ value of $<0.05$ was considered statistically significant.

Unless stated otherwise, data are expressed as means with standard error of the mean (SEM).

\section{Results}

The demographic characteristics of all participants are summarized in Table 1. Changes in renin, aldosterone, and the ARR during treatment are displayed in Table 2.

\section{Hydralazine}

Hydralazine was administered at a median dosage of $150 \mathrm{mg}$ per day (interquartile range (IQR) $75-150 \mathrm{mg}$ ). During treatment with hydralazine, APRC rose from $19 \pm 3$ to $25 \pm 4$ $\mathrm{mIU} / \mathrm{L}$, which was of borderline statistical significance $(p=0.067)$. PAC, on the other hand, did not change significantly $(410 \pm 68$ vs $360 \pm 58 \mathrm{pmol} / \mathrm{L}, p=0.216)$. The ARR fell significantly from $38 \pm 10$ to $24 \pm 4(p=0.017)$. Multiple regression analysis did not reveal age, sex, BMI, baseline blood pressure, or drug dosage to be significant predictors for the percentage change in APRC, PAC, and ARR values. 
Table 1 Demographic baseline characteristics of all study populations

\begin{tabular}{llll}
\hline & Hydralazine $(n=26$ & Doxazosin $(n=21)$ & Verapamil $(n=15$ \\
\hline Male:female (ratio) & $7: 19$ & $14: 6$ & $9: 6$ \\
Age (years) & $46(3)$ & $50(2)$ & $45(3)$ \\
Height (males) $(\mathrm{cm})$ & $177(2)$ & $176(2)$ & $177(2)$ \\
Height (females) $(\mathrm{cm})$ & $163(1)$ & $165(1)$ & $164(1)$ \\
Weight (males) $(\mathrm{kg})$ & $85(2)$ & $83(2)$ & $84(4)$ \\
Weight $($ females) $(\mathrm{kg})$ & $67(3)$ & $71(3)$ & $70(4)$ \\
BMI $\left(\mathrm{kg} / \mathrm{m}^{2}\right)$ & $25(1)$ & $27(1)$ & $27(1)$ \\
Participants with BMI $>25(\%)$ & $54 \%$ & $55 \%$ & $60 \%$ \\
Systolic blood pressure $(\mathrm{mmHg})$ & $159(5)$ & $165(4)$ & $152(6)$ \\
Diastolic blood pressure $(\mathrm{mmHg})$ & $98(3)$ & $102(3)$ & $95(4)$ \\
Mean arterial pressure & $119(3)$ & $124(3)$ & $113(4)$ \\
Heart rate $(\mathrm{BPM})$ & $72(2)$ & $76(3)$ & $69(2)$ \\
Plasma sodium $(\mathrm{mmol} / \mathrm{L})$ & $143(1)$ & $141(1)$ & $140(1)$ \\
Plasma potassium $(\mathrm{mmol} / \mathrm{L})$ & $4.2(0.2)$ & $4.4(0.1)$ & $4.3(0.1)$ \\
Plasma creatinine $(\mu \mathrm{mol} / \mathrm{L})$ & $99(9)$ & $104(6)$ & $90(5)$ \\
\hline
\end{tabular}

All data expressed as means and standard error of the mean (SEM)
Table 2 Effect of the medications on average levels of PAC, APRC, and ARR

\begin{tabular}{lllll}
\hline & & Untreated & Treated & $p$ value \\
\hline Hydralazine & PAC & $410(68)$ & $360(58)$ & 0.216 \\
& APRC & $19(3)$ & $25(4)$ & 0.067 \\
& ARR & $38(10)$ & $24(4)$ & 0.017 \\
Doxazosin & PAC & $470(49)$ & $330(28)$ & 0.028 \\
& APRC & $19(2)$ & $20(2)$ & 0.639 \\
\multirow{5}{*}{ Verapamil } & ARR & $30(5)$ & $20(3)$ & 0.020 \\
& PAC & $420(58)$ & $326(35)$ & 0.141 \\
& APRC & $21(3)$ & $21(4)$ & 0.840 \\
& ARR & $27(8)$ & $18(3)$ & 0.188 \\
\hline
\end{tabular}

All data expressed as means and standard error of the mean (SEM)

\section{Doxazosin}

Doxazosin was administered at a median dosage of $10 \mathrm{mg}$ per day (IQR 3-20 mg). Doxazosin did not significantly affect APRC levels post-treatment $(19 \pm 2$ vs $20 \pm 2$ $\mathrm{mIU} / \mathrm{L}, p=0.639)$. However, declines in PAC $(470 \pm 49$ vs $330 \pm 28 \mathrm{pmol} / \mathrm{L})$ and ARR $(30 \pm 5$ vs $20 \pm 3)$ were both statistically significant ( $p=0.028$ and $p=0.020$, respectively). Multiple regression analysis did not reveal age, sex, BMI, baseline blood pressure, or drug dosage to be significant predictors for the percentage change in APRC, PAC, and ARR values.

\section{Verapamil}

Verapamil was administered at a median dosage of $240 \mathrm{mg}$ per day (IQR $240-480 \mathrm{mg}$ ). The mean values for pre- and post-treatment levels of APRC ( $21 \pm 3$ vs $21 \pm 4 \mathrm{mlU} / \mathrm{L}) \mathrm{did}$ not significantly differ. PAC ( $420 \pm 58$ vs $326 \pm 35 \mathrm{pmol} / \mathrm{L})$ and the ARR ( $27 \pm 8$ vs $18 \pm 3$ ) fell after administration of verapamil, but changes were very variable and not statistically significant ( $p=0.141$ and $p=0.188$ respectively).

Individual patient data of the ARR before and after the three forms of treatment are presented in Fig. 1.

\section{Discussion}

The primary findings of our study are that both hydralazine and doxazosin resulted in significant falls in the ARR, an outcome not in keeping with conventional wisdom on the topic. Hydralazine's changes seem to have been primarily driven by changes in the APRC while doxazosin's effect seemed to have conversely been the result of changes in PAC. In addition, while the changes in PAC and ARR values after verapamil administration were not statistically significant, the magnitude of their declines was nonetheless rather large in our opinion. Given that verapamil was our smallest study population, comprising only 15 participants, it is possible that a larger population would garner a clearer picture regarding verapamil's potential effects on the RAAS. Regardless, we feel that it would be negligent to conclude that verapamil has no effect on the ARR based on the nonsignificant $p$ value obtained in our statistical analysis.

The effect of hydralazine on aldosterone levels has been largely overlooked in scientific research, with no studies regarding its effect on the ARR published. A number of studies could be found regarding the effect of hydralazine on renin levels. In all studies, hydralazine administration resulted in rises in renin levels, with the rise being 

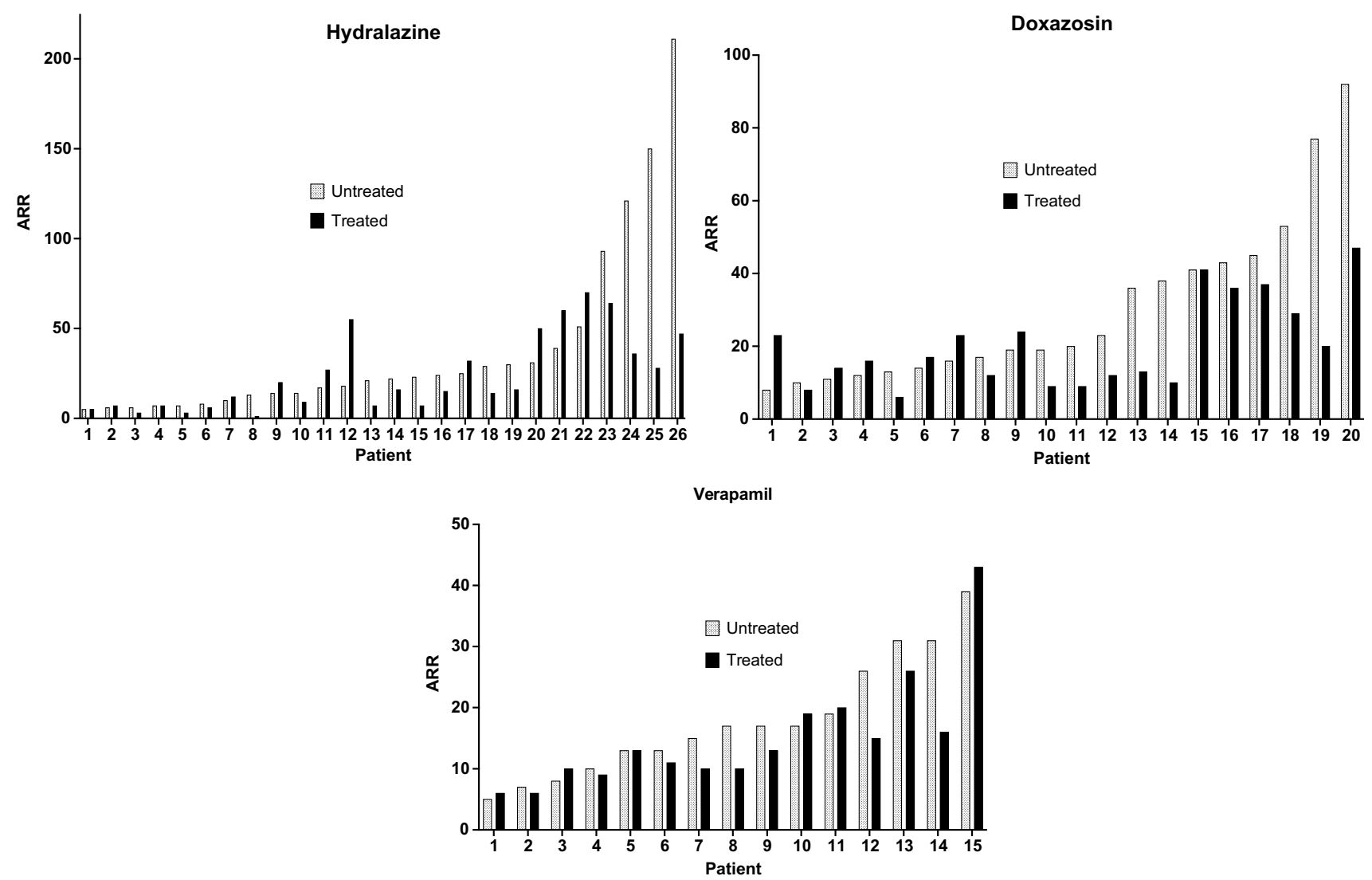

Fig. 1 Aldosterone-to-renin ratio (ARR) of individual participants comparing untreated and treated values, arranging in order of ascending untreated ARR values

statistically significant in all but one study [4-9]. Hydralazine has been found in previous studies to result in increased sympathetic outflow [10-13] and, hence, increased renin release [14-17]. This interplay between increased sympathetic outflow and $\beta_{1}$-adrenoceptor-mediated renin activation could be the driving factor in our findings regarding hydralazine.

The most notable study concerning the effect of doxazosin on aldosterone, renin, and the ARR was performed by Mulatero et al. in a population with primary aldosteronism [3]. The findings of that study are well in line with our own, with significant declines in PAC and ARR being noted, as well as a statistically insignificant effect on APRC. The magnitude of these effects was considerably smaller than in our study. However, doxazosin's apparent aldosteronesuppressing effects would be presumably dampened by the autonomous excessive production of aldosterone that typifies PA. Thus, the study by Mulatero et al. and our own could dovetail nicely in demonstrating the spectrum of the effects that doxazosin has on the two primary patient types who typically undergo PA screening, that being essential hypertensives and patients with as-yet undiagnosed PA. Of the few other studies performed regarding doxazosin, they typically focused on the effect it had on renin levels, without a thorough investigation of aldosterone or ARR changes [18-20]. There is some evidence that doxazosin may marginally increase renin release [21-23], but no notable investigations have been performed regarding the effect of doxazosin on aldosterone levels nor the ARR beyond our own and that of Mulatero and colleagues.

Unlike hydralazine and doxazosin, verapamil has had a fair amount of scientific investigation regarding its effects on renin and, to a lesser extent, aldosterone. While the vast majority of studies found that renin and aldosterone were unaffected by verapamil [24-31], this was not a universal finding. For example, Sun and colleagues noted that verapamil resulted in a significant rise in PRA in their study [32]. They hypothesized that this was the result of L-type calcium channel blockade resulting in higher intracellular calcium levels and consequently lower renin uptake in blood cells and, therefore, higher renin concentrations in plasma. Zacharieva and coworkers, as well as Frishman and colleagues, also noted a rise in PRA upon verapamil administration $[33,34]$. Conversely, Buckley and coworkers found that verapamil suppressed the entire RAAS system [35]. Concerningly, there is evidence that verapamil attenuates the 
aldosterone response to angiotensin-II [36-40]. This could be a possible explanation for the non-significant decline noted in our own investigation. It should be stressed that while verapamil has been fairly thoroughly investigated, vis-a-vis, its effect on renin levels, the volume of research regarding aldosterone is far from comprehensive. To date, to the best of our knowledge, our study is the only investigation performed observing the effect of verapamil on individual ARR levels.

The primary clinical implication of our findings is a warning against complacency with regard to the usage of the abovementioned drugs when screening for PA. The level of research regarding these drugs and their effect on the ARR is simply far from authoritative. While it is true that these drugs have far less direct interaction with the RAAS in their primary mechanisms of action than many other antihypertensives and thus theoretically are less likely to affect the ARR values of patients undergoing PA screening, it is unwise to assume that they are inert when screening for PA. Such a lack of prudence would in all likelihood result in a significant number of missed diagnoses.

We hope that these findings demonstrate the clear and pressing need for greater research on this topic. Almost no research regarding these drugs and their effect on the ARR have been performed, and inasmuch as data are available, the majority of these are now roughly 40 years old.

The main weakness of our study was that our patients had blood samples taken from the supine position, despite current guidelines advising that patients be in the seated position for blood samples when screening for PA. However, we deliberately wanted to avoid posture-related variations in renin and aldosterone levels as the upright position may have variable effects on plasma aldosterone. Previous research has indicated that the ARR is less variable when measured in the supine position [41]. An additional limitation was our somewhat small population sizes. Having larger sample sizes would have given greater strength to our findings and, in the case of verapamil, would rule out the possibility of a type II error.

\section{Conclusions and Perspectives}

Our data show that hydralazine resulted in a borderline significant rise in active plasma renin concentration and a significant fall in the aldosterone-to-renin ratio. Doxazosin caused declines in both plasma aldosterone concentration and the aldosterone-to-renin ratio. Verapamil did not significantly affect any of our outcome variables though it did result in a large but non-significant decline in both PAC and ARR. Based on our findings, we conclude that using these drugs when screening for PA with no regard for their potential effects on the ARR to be unadvisable. While it is possible that they are indeed the best option when full antihypertensive drug cessation is infeasible, the potential effects of these agents must still be taken into account when interpreting the aldosterone-to-renin ratio. Additionally, we see a clear and pressing need for further studies on this topic in larger patient groups with or without evidence of primary aldosteronism. We believe that our findings emphasize the importance of standardized test conditions when measuring the ARR in order to make accurate interpretation feasible. Clinicians should weigh up the risks and benefits of drug cessation when performing ARR testing, and when cessation isn't viable, clinicians should be aware of the potentially unpredictable changes to the ARR that can result even by drugs deemed relatively inconsequential to the ARR. In patients using medication at the time of ARR testing, the increased likelihood of both type I and II errors should be kept in mind.

Author Contribution All authors contributed to the study conception and design. Material preparation, data collection, and analysis were performed by Peter W. de Leeuw. The first draft of the manuscript was written by Gregory P. Veldhuizen and all authors commented on previous versions of the manuscript. All authors read and approved the final manuscript.

Data Availability All data and materials as well as software application support our claims and comply with field standards. Data are available upon request.

\section{Declarations}

Ethics Approval All studies described in this paper were approved by the local Medical Ethical Committee.

Consent to Participate Informed consent was obtained from all individuals who participated in the studies described in this paper.

Consent for Publication By their consent to participate in the studies, patients also consented to the (anonymous) publication of the study results.

Conflict of Interest The authors declare no competing interests.

Open Access This article is licensed under a Creative Commons Attribution 4.0 International License, which permits use, sharing, adaptation, distribution and reproduction in any medium or format, as long as you give appropriate credit to the original author(s) and the source, provide a link to the Creative Commons licence, and indicate if changes were made. The images or other third party material in this article are included in the article's Creative Commons licence, unless indicated otherwise in a credit line to the material. If material is not included in the article's Creative Commons licence and your intended use is not permitted by statutory regulation or exceeds the permitted use, you will need to obtain permission directly from the copyright holder. To view a copy of this licence, visit http://creativecommons.org/licenses/by/4.0/. 


\section{References}

1. Funder JW, Carey RM, Mantero F, Murad MH, Reincke M, Shibata $\mathrm{H}$, et al. The management of primary aldosteronism: case detection, diagnosis, and treatment: an Endocrine Society Clinical Practice Guideline. J Clin Endocrinol Metab. 2016;101(5):1889916. https://doi.org/10.1210/jc.2015-4061.

2. Alnazer RM, Veldhuizen GP, Kroon AA, de Leeuw PW. The effect of medication on the aldosterone-to-renin ratio. A critical review of the literature. J Clin Hypertens (Greenwich). 2021;23(2):20814. https://doi.org/10.1111/jch.14173.

3. Mulatero P, Rabbia F, Milan A, Paglieri C, Morello F, Chiandussi $\mathrm{L}$, et al. Drug effects on aldosterone/plasma renin activity ratio in primary aldosteronism. Hypertension. 2002;40(6):897-902. https://doi.org/10.1161/01.hyp.0000038478.59760.41.

4. Byyny RL, Nies AS, LoVerde ME, Mitchell WD. A double-blind, randomized, controlled trial comparing pinacidil to hydralazine in essential hypertension. Clin Pharmacol Ther. 1987;42(1):50-7. https://doi.org/10.1038/clpt.1987.107.

5. Leenen FH, Smith DL, Farkas RM, Reeves RA, Marquez-Julio A. Vasodilators and regression of left ventricular hypertrophy Hydralazine versus prazosin in hypertensive humans. Am J Med. 1987;82(5):969-78. https://doi.org/10.1016/0002-9343(87) 90160-4.

6. Gomes AS, Sinaiko AR, Tobian L, Cohn JN, Formanek G, Amplatz K. Hydralazine and the tourniquet test in renal vein renin sampling: a comparison. Radiology. 1983;146(3):657-61. https:// doi.org/10.1148/radiology.146.3.6338555.

7. Gomes AS, Sinaiko AR, Tobian L, Cohn JN, Formanek AG, Roe DJ, et al. Renal vein renin sampling in essential hypertension using hydralazine and the tourniquet test. Radiology. 1984;153(3):619-23. https://doi.org/10.1148/radiology.153.3. 6387785 .

8. Thind GS, Montojo PM, Johnson A, Amin E. Enhancement of renal venous renin ratios by intravenous hydralazine in renovascular hypertension. Am J Cardiol. 1984;53(1):109-15. https://doi. org/10.1016/0002-9149(84)90693-3.

9. Ueda H, Yagi S, Kaneko Y. Hydralazine and plasma renin activity. Arch Intern Med. 1968;122(5):387-91.

10. Kandler MR, Mah GT, Tejani AM, Stabler SN, Salzwedel DM. Hydralazine for essential hypertension. Cochrane Database Syst Rev. 2011(11):CD004934. https://doi.org/10.1002/14651858. CD004934.pub4.

11. Riddiough MA. Preventing, detecting and managing adverse reactions of antihypertensive agents in the ambulant patient with essential hypertension. Am J Hosp Pharm. 1977;34(5):465-79.

12. McComb MN, Chao JY, Ng TM. Direct vasodilators and sympatholytic agents. J Cardiovasc Pharmacol Ther. 2016;21(1):3-19. https://doi.org/10.1177/1074248415587969.

13. Kirsten R, Nelson K, Kirsten D, Heintz B. Clinical pharmacokinetics of vasodilators. Part I Clin Pharmacokinet. 1998;34(6):45782. https://doi.org/10.2165/00003088-199834060-00003.

14. Davis JO, Freeman RH. Mechanisms regulating renin release. Physiol Rev. 1976;56(1):1-56. https://doi.org/10.1152/physrev. 1976.56.1.1.

15. Torretti J. Sympathetic control of renin release. Annu Rev Pharmacol Toxicol. 1982;22:167-92. https://doi.org/10.1146/annurev. pa.22.040182.001123.

16. Guazzi MD, Barbier P, Loaldi A, Montorsi P, Polese A, Tosi E, et al. Intrarenal beta-receptor and renal baroreceptor interaction in the control of the renin response to transient reduction of the renal perfusion pressure in man. J Hypertens. 1985;3(1):39-45. https://doi.org/10.1097/00004872-198502000-00007.

17. Zanchetti AS. Neural regulation of renin release: experimental evidence and clinical implications in arterial hypertension.
Circulation. 1977;56(5):691-8. https://doi.org/10.1161/01.cir. 56.5.691.

18. Shionoiri H, Yasuda G, Yoshimura H, Umemura S, Miyajima E, Miyakawa T, et al. Antihypertensive effects and pharmacokinetics of single and consecutive administration of doxazosin in patients with mild to moderate essential hypertension. J Cardiovasc Pharmacol. 1987;10(1):90-5. https://doi.org/10.1097/00005344-19870 7000-00013.

19. Stokes GS, Johnston HJ, Okoro EO, Boutagy J, Monaghan JC, Marwood JF. Comparative and combined efficacy of doxazosin and enalapril in hypertensive patients. Clin Exp Hypertens. 1994;16(6):709-27. https://doi.org/10.3109/10641969409078021.

20. Oliveros-Palacios MC, Godoy-Godoy N, Colina-Chourio JA. Effects of doxazosin on blood pressure, renin-angiotensin-aldosterone and urinary kallikrein. Am J Cardiol. 1991;67(2):157-61.

21 De Leeuw PW, Van Es PN, De Bos R, Birkenhäger WH. Role of alpha 1 and alpha 2 adrenergic receptors in the human hypertensive kidney. Hypertension. 1987;9(6 Pt 2):III210-2.

22. de Leeuw PW, van Es PN, De Bos R, Birkenhager WH. Acute renal effects of doxazosin in man. Br J Clin Pharmacol. 1986;21(Suppl 1):41S-S43. https://doi.org/10.1111/j.1365-2125. 1986.tb02852.x.

23. de Leeuw PW, de Bos R, van Es PN, Birkenhager WH. Effect of sympathetic stimulation and intrarenal alpha-blockade on the secretion of renin by the human kidney. Eur J Clin Invest. 1985;15(4):166-70. https://doi.org/10.1111/j.1365-2362.1985. tb00163.x.

24 Fagher B, Henningsen N, Hulthen L, Katzman P, Thulin T. Antihypertensive and renal effects of enalapril and slow-release verapamil in essential hypertension. A double-blind, randomized study. Eur J Clin Pharmacol. 1990;39(Suppl 1):S41-3. https://doi. org/10.1007/BF01409207.

25. Cruickshank JK, Anderson NM, Wadsworth J, Young SM, Jepson E. Treating hypertension in black compared with white noninsulin dependent diabetics: a double blind trial of verapamil and metoprolol. BMJ. 1988;297(6657):1155-9. https://doi.org/10. 1136/bmj.297.6657.1155.

26. Chellingsworth MC, Kendall MJ. Effects of nifedipine, verapamil and diltiazem on renal function. Br J Clin Pharmacol. 1988;25(5):599-602. https://doi.org/10.1111/j.1365-2125.1988. tb03351.x.

27. Stadler P, Leonardi L, Riesen W, Ziegler W, Marone C, BerettaPiccoli C. Cardiovascular effects of verapamil in essential hypertension. Clin Pharmacol Ther. 1987;42(5):485-92. https://doi.org/ 10.1038/clpt.1987.185.

28. Agabiti-Rosei E, Muiesan ML, Romanelli G, Castellano M, Beschi M, Corea L, et al. Similarities and differences in the antihypertensive effect of two calcium antagonist drugs, verapamil and nifedipine. J Am Coll Cardiol. 1986;7(4):916-24. https://doi. org/10.1016/s0735-1097(86)80357-6.

29. Muiesan G, Agabiti-Rosei E, Romanelli G, Muiesan ML, Castellano M, Beschi M. Adrenergic activity and left ventricular function during treatment of essential hypertension with calcium antagonists. Am J Cardiol. 1986;57(7):44D-D49. https://doi.org/ 10.1016/0002-9149(86)90805-2.

30. Sorensen SS, Thomsen OO, Danielsen H, Pedersen EB. Effect of verapamil on renal plasma flow, glomerular filtration rate and plasma angiotensin II, aldosterone and arginine vasopressin in essential hypertension. Eur J Clin Pharmacol. 1985;29(3):257-61. https://doi.org/10.1007/BF00544077.

31. Muiesan G, Agabiti-Rosei E, Castellano M, Alicandri CL, Corea L, Fariello R, et al. Antihypertensive and humoral effects of verapamil and nifedipine in essential hypertension. J Cardiovasc Pharmacol. 1982;4(Suppl 3):S325-9.

32. Sun N, Hong T, Zhang R, Yang X. The effects of verapamil SR and bisoprolol on reducing the sympathetic nervous system's 
activity. Hypertens Res. 2000;23(5):537-40. https://doi.org/10. 1291/hypres.23.537.

33. Zacharieva S, Koev D, Matrozov P, Tcharaktchiev D, Stoeva I, Andonova K. Effect of verapamil on renin-angiotensin-aldosterone system, urinary 6-keto prostaglandin F1 alpha and aldosterone response to metoclopramide in normal man. Acta Physiol Pharmacol Bulg. 1989;15(4):31-6.

34 Frishman WH, Klein NA, Klein P, Strom JA, Tawil R, Strair R, et al. Comparison of oral propranolol and verapamil for combined systemic hypertension and angina pectoris. A placebocontrolled double-blind randomized crossover trial. Am J Cardiol. 1982;50(5):1164-72. https://doi.org/10.1016/0002-9149(82) 90438-6.

35. Buckley JW, Hedner T, Masotto C, Posvar E, Negro-Villar A, Cubeddu LX. Comparative effects of verapamil and volume overload on atrial natriuretic factors and the renin-angiotensin aldosterone-vasopressin system. J Clin Pharmacol. 1992;32(12):1120-7.

36. Kotchen TA, Galla JH, Luke RG. Effects of calcium on renin and aldosterone in the rat. Am J Physiol. 1977;232(4):E388-93. https://doi.org/10.1152/ajpendo.1977.232.4.E388.

37. Opocher G, Rocco S, Murgia A, Mantero F. Effect of verapamil on aldosterone secretion in primary aldosteronism. J Endocrinol Invest. 1987;10(5):491-4. https://doi.org/10.1007/BF03348177.
38. Magometschnigg D, Hortnagl H, Rameis H. Diltiazem and verapamil: functional antagonism of exogenous noradrenaline and angiotensin II in man. Eur J Clin Pharmacol. 1984;26(3):303-7. https://doi.org/10.1007/BF00548759.

39. de Leeuw PW, Birkenhager WH. Effects of verapamil in hypertensive patients. Acta Med Scand Suppl. 1984;681:125-8. https:// doi.org/10.1111/j.0954-6820.1984.tb08686.x.

40. Guthrie GP Jr, McAllister RG Jr, Kotchen TA. Effects of intravenous and oral verapamil upon pressor and adrenal steroidogenic responses in normal man. J Clin Endocrinol Metab. 1983;57(2):339-43. https://doi.org/10.1210/jcem-57-2-339.

41. Veldhuizen GP, Alnazer RM, Kroon AA, de Leeuw PW. Confounders of the aldosterone-to-renin ratio when used as a screening test in hypertensive patients: a critical analysis of the literature. J Clin Hypertens (Greenwich). 2021;23(2):201-7. https:// doi.org/10.1111/jch.14117.

Publisher's Note Springer Nature remains neutral with regard to jurisdictional claims in published maps and institutional affiliations. 